\title{
Solid-Pseudopapillary Neoplasm of the Pancreas: A 63-Case Analysis of Clinicopathologic and Immunohistochemical Features and Risk Factors of Malignancy
}

This article was published in the following Dove Press journal:

Cancer Management and Research

\author{
Hongchun Chen (iD) ${ }^{1,2}$ \\ Yuchen Huang $\mathbb{D}^{1,2}$ \\ Ningning Yang $\mathbb{D}^{1,2}$ \\ Wentian Yan (iD ${ }^{1,2}$ \\ Ruxue Yang $\mathbb{( D}^{3}$ \\ Shan Zhang $\mathbb{D}^{4}$ \\ Panpan Yang (D) \\ Nan Li (iD) ${ }^{1,2}$ \\ Zhenzhong Feng $\mathbb{D}^{1,2}$
}

'Department of Pathology, Bengbu Medical College, Bengbu, Anhui Province, 233000, People's Republic of China; ${ }^{2}$ Department of Pathology, First Affiliated Hospital of Bengbu Medical College, Bengbu, Anhui Province, 233000, People's Republic of China; ${ }^{3}$ Department of Pathology, First Affiliated Hospital of Anhui Medical University, Hefei, Anhui Province, 230000, People's Republic of China; ${ }^{4}$ Department of Pathology, Second People's Hospital of Hefei, Hefei, Anhui Province, 230000, People's Republic of China; ${ }^{5}$ Department of Pathology, Second Affiliated Hospital of Anhui Medical University, Hefei, Anhui Province, 230000, People's Republic of China
Correspondence: Zhenzhong Feng Department of Pathology, First Affiliated Hospital of Bengbu Medical College, No. 287 Changhuai Road, Longzihu District, Bengbu, Anhui, 233000, People's Republic of China

Tel +86 I 5055289508

Email fzzl829730I626@I63.com
Purpose: Solid-pseudopapillary neoplasm (SPN) of the pancreas, a rare tumor, has low malignant potential. However, some patients develop metastasis and recurrence after resection, with aggressive biological behaviors. This study aimed to explore the features and risk factors associated with the aggressive biological behaviors of SPNs.

Patients and Methods: We retrospectively analyzed the clinicopathological and long-term follow-up data of 63 patients diagnosed with SPN at the First Affiliated Hospital of Bengbu Medical College between January 2007 and February 2019.

Results: Sixty-three patients presented atypical clinical symptoms. The median tumor size was $7.0 \mathrm{~cm}$ (range, $2.4-17 \mathrm{~cm}$ ), and imaging features were solid and cystic or solid tumors with uneven density. Frequent and diffuse nuclear LEF1 protein expression $(94.2 \%)$ was observed with LEF1 having a higher sensitivity and specificity. Overall survival significantly correlated with tumor size, Ki-67 index, and lymph node metastasis $(P<0.05)$.

Conclusion: SPN is a rare low-grade malignancy with a specific pseudopapillary structure. LEF1 is an effective biomarker of SPNs. Although SPNs generally display indolent biological behavior, a large tumor size, high proliferation index, and lymph node metastasis may be risk factors for the aggressive behavior and poor prognosis of SPN.

Keywords: pancreatic tumor, LEF1, retrospective study, overall survival, metastasis

\section{Introduction}

Solid-pseudopapillary neoplasm (SPN) of the pancreas, an extremely rare exocrine pancreatic tumor, that accounts for approximately $1-3 \%$ of all exocrine tumors, usually occurs in young women. ${ }^{1}$ Most patients have nonspecific symptoms, including subtle abdominal pain and discomfort, or nonspecific signs, such as the presence of an abdominal mass, while a few patients present with back pain, nausea, vomiting, and jaundice. ${ }^{2}$ The most common site for an SPN is the distal pancreas, followed by the retroperitoneal area. ${ }^{3}$ An SPN is composed of poorly cohesive monomorphic epithelial cells that form a heterogeneous growth pattern of solid and pseudopapillary and pseudocystic structures, usually along with hemorrhagic degeneration. ${ }^{4}$ Microscopically, an SPN is similar to other pancreatic neoplasms, such as well-differentiated pancreatic neuroendocrine tumors (NETs) and pancreatic ductal adenocarcinomas (PDACs). Thus, pathological diagnosis is 
difficult when limited to only morphological characteristics. ${ }^{5}$ Clinically, several biomarkers, including CD56, CD99, $\beta$-catenin, Ki-67, and progesterone receptor (PR), are used for a comprehensive cancer diagnosis. ${ }^{6,7}$ However, there are currently no diagnostic biomarkers specifically for SPNs.

Most SPNs have an inert or low-grade malignant potential, and the overall prognosis is good. ${ }^{8}$ However, up to $20 \%$ of SPNs show local recurrence or distant metastasis after complete surgical resection. ${ }^{9,10}$ It has been shown that a small number of SPNs have aggressive biological behaviors. However, there are no definite clinicopathological parameters to predict the malignant biological behavior of SPNs. ${ }^{11}$ Thus, the purpose of this study was to explore the clinicopathological features of SPNs and identify risk factors and new effective markers associated with the aggressive biological behavior of SPNs to understand and predict the malignancy of SPNs.

\section{Patients and Methods}

\section{Study Design and Patients}

This retrospective study was approved by the Ethics Committee of the First Affiliated Hospital of Bengbu Medical College (No. 2020057) and was conducted according to the tenets of the Declaration of Helsinki. Written informed consent was obtained from the patients or their families.

Sixty-three patients diagnosed with SPNs at the Department of Pathology between January 2011 and February 2019 were included in the study. We also included an immunohistochemical control group comprising 80 patients ( 5 with pancreatoblastoma; 25 , well differentiated pancreatic NET (G1 or 2); 25, PDAC; and 25, normal pancreatic tissue). The control group was a group of patients that were randomly selected over the same time period and who had no previous history of radiotherapy or chemotherapy and did not have other cancers. Three pathologists reviewed patient data to confirm the diagnosis. All patients were followed up telephonically using outpatient records.

\section{Immunohistochemistry}

Tissue specimens were fixed in $10 \%$ neutral buffered formalin and incubated at $60{ }^{\circ} \mathrm{C}$ for $1 \mathrm{~h}$ after being sliced into 4- $\mu \mathrm{m}$ thick sections. EnVision's two-step method was adopted for immunohistochemical staining.
The primary antibody was replaced with phosphatebuffered saline as the negative control, and the known positive tissue was used as the positive control. The primary immunohistochemical markers were LEF1 (Abcam Biotech, Inc. Cambridge, UK), cytokeratin, $\beta$ catenin, vimentin, CD10, $\alpha 1$-antichymotrypsin, chromogranin A, synaptophysin (Syn), carcinoembryonic antigen, CD99, neuron-specific enolase, CD56, PR, and Ki67 (Maixin Biotech, Inc. Fuzhou, China). All immunohistochemical labeling was performed using the streptavidin-peroxidase system (KIT-9720; Ultrasensitive TM S-P, Maixin Biotech, Inc.). Diaminobenzidine tetrahydrochloride substrate was used as the chromogen in

Table I Clinicodemographic Patient Characteristics $(n=63)$

\begin{tabular}{|c|c|c|}
\hline Characteristics & & Value \\
\hline Sex & $\begin{array}{l}\text { Male } \\
\text { Female }\end{array}$ & $\begin{array}{l}12(19.0 \%) \\
51(81.0 \%)\end{array}$ \\
\hline $\begin{array}{l}\text { Age (years), median } \\
\text { (range) }\end{array}$ & $\begin{array}{l}\text { Male } \\
\text { Female }\end{array}$ & $\begin{array}{l}26.5(13-67) \\
33(14-66)\end{array}$ \\
\hline Location, n (\%) & $\begin{array}{l}\text { Head } \\
\text { Body } \\
\text { Tail } \\
\text { Body and tail } \\
\text { Outside pancreas }\end{array}$ & $\begin{array}{l}16(25.4 \%) \\
5(7.9 \%) \\
17(27.0 \%) \\
22(34.9 \%) \\
3(4.8 \%)\end{array}$ \\
\hline Symptomatic, n (\%) & & $33(52.4 \%)$ \\
\hline $\begin{array}{l}\text { Recurrence/metastasis, } \\
\text { n (\%) }\end{array}$ & & 9 (15.4\%) \\
\hline $\begin{array}{l}\text { Follow-up (months), } \\
\text { median (range) }\end{array}$ & & $42(11-126)$ \\
\hline $\begin{array}{l}\text { Tumor size }(\mathrm{cm}) \text {, median } \\
\text { (range) }\end{array}$ & & $7.0(2.4-17)$ \\
\hline Tumor infiltration & $\begin{array}{l}\text { No invasion } \\
\text { Pancreatic } \\
\text { parenchyma } \\
\text { Peripancreatic fat } \\
\text { infiltration }\end{array}$ & $\begin{array}{l}36(57.1 \%) \\
12(19.0 \%) \\
15(23.8 \%)\end{array}$ \\
\hline Mitosis (I/I0 HPF) & & 10 (I5.9\%) \\
\hline Cellular atypia & & $2(3.2 \%)$ \\
\hline Vascular invasion & & 7 (II.1\%) \\
\hline Lymph node metastasis & & $5(7.9 \%)$ \\
\hline Necrosis & & 31 (49.2\%) \\
\hline Calcification & & $36(57.1 \%)$ \\
\hline
\end{tabular}


DAB staining, which was performed using a DAB kit (Maixin Biotech, Inc.).

\section{Statistical Analysis}

The Kaplan-Meier method was used for the univariate disease-free survival analysis, and the survival time between groups was compared using the Log rank test. Cox regression analysis was used for multivariate analysis. Overall survival (OS) was defined as the period from diagnosis to recurrence, metastasis, death, or the end of follow-up. All statistical analyses were performed using SPSS 22.0 software for Windows (IBM, New York, USA). All $P$-values were two-sided, and $P<0.05$ was considered statistically significant.

\section{Results}

\section{Clinical Features}

A total of 63 patients with SPN with a median age of 32 years (range, 13-67 years) were included (Table 1). Of them, 51 were female (median age: 33 years [range,
14-66 years]) and 12 were male (median age: 26.5 years [range, 13-67 years]). The patients presented nonspecific clinical symptoms, including abdominal mass ( $\mathrm{n}$ $=15,23.8 \%)$, abdominal pain $(\mathrm{n}=11,17.5 \%)$, and abdominal pain with distension $(\mathrm{n}=7,11.1 \%)$. Overall, 30 patients $(47.6 \%)$ were asymptomatic. Computed tomography (CT) mainly showed welldefined mixed density nodules or mass shadows with varying degrees of internal bleeding and cystic degeneration. With respect to location, the most common was the body and tail $(\mathrm{n}=22,34.9 \%)$, followed by the tail $(\mathrm{n}=17,27.0 \%)$, head $(\mathrm{n}=16,25.4 \%)$, and body $(\mathrm{n}=5$, $7.9 \%$ ) of the pancreas. In three patients $(4.8 \%)$, the tumor was located in the retroperitoneum outside the pancreas.

\section{Pathological Characteristics}

The median tumor size was $7.0 \mathrm{~cm}$ (range, 2.4-17 cm). Visually, the SPN appeared as a well-defined mass, generally large, round or quasi-round, and solid or

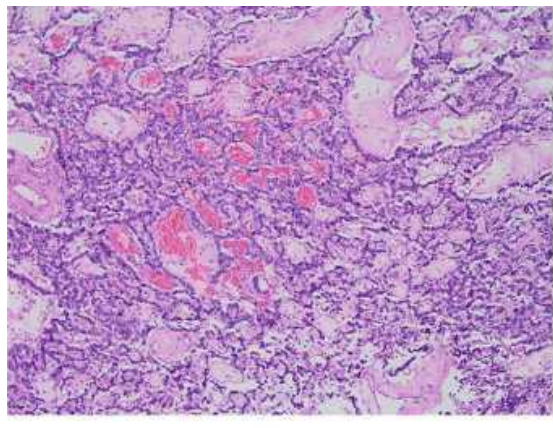

A

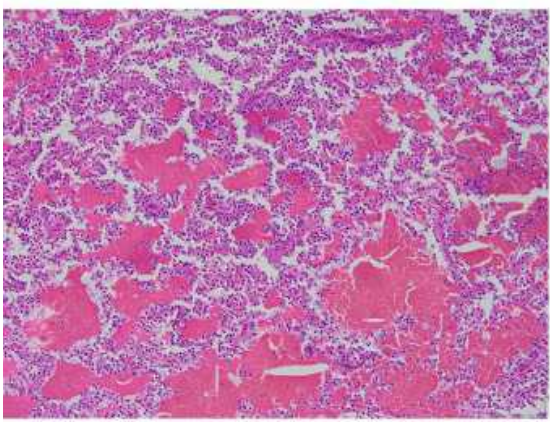

D

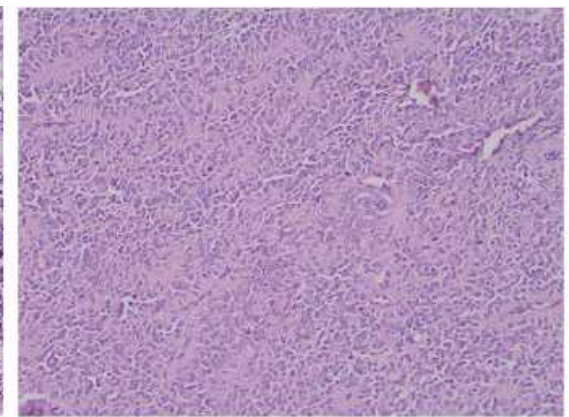

B

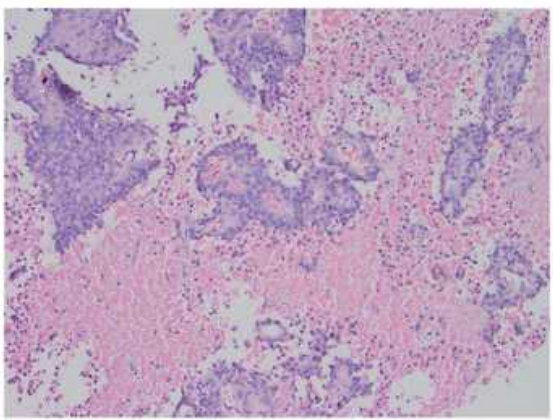

E

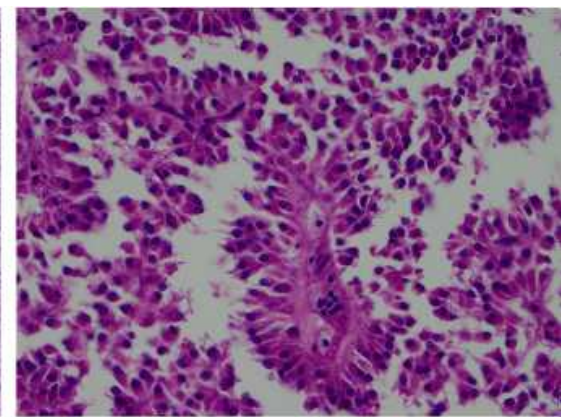

C

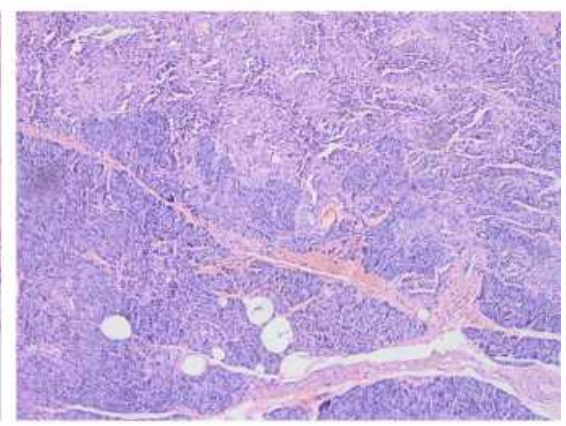

$\mathbf{F}$

Figure I Histopathological characteristics of solid-pseudopapillary neoplasm (SPN) based on hematoxylin and eosin (H\&E) staining. (A) The tumor cells have various shapes, forming clusters of different sizes with hemorrhage, cystic, and pseudopapillary structures (magnification, $\times 100$ ). (B) The tumor is mainly a solid area, with less interstitial components (magnification, $\times 200$ ). (C) The tumor cell cytoplasm is eosinophilic or lightly stained, the nucleus is oval, the chromatin is fine, and mitotic images are rare (magnification, $\times 400$ ). (D) The tumor has a wide hemorrhagic area with cystic degeneration (magnification, $\times 200$ ). (E) The cells distant from the blood vessels degenerate and fall off, and the tumor cells around the blood vessels surround the blood vessels to form pseudopapillary structures (magnification, $\times 200)$. (F) The tumor infiltrates surrounding normal pancreatic tissue (magnification, $\times 100$ ). 
cystic. Most tumors had fibrous soft capsules, while some were jelly-like. The solid components with a grayred or gray-white fish-like appearance were soft and fragile and were hemorrhagic in the cystic region. Histologically (Figure 1A-C), most SPNs were composed of solid and pseudopapillary arrangements surrounded by hemorrhagic and necrotic areas (Figure 1D-E). The solid structures had mixed small-sized and medium-sized tumor cells, without obvious atypia. In the pseudopapillary area, the tumor tissues formed a radial pseudopapillary structure with fine fibrous vessels as the axis, and the surface cells were mostly arranged in layers. Tumor focal necrosis and calcification occurred in $31(49.2 \%)$ and $36(57.1 \%)$ cases, respectively. In total, 15 patients $(23.8 \%)$ and 12 patients $(19.0 \%)$ showed infiltration of the peripancreatic fat and invasion of the pancreatic parenchyma (Figure 1F), respectively. Ten patients (15.9\%) had mitotic figures in $>1 / 10$ high-power field, seven patients (11.1\%) had vascular tumor thrombus, and five patients (7.9\%) had lymph node metastasis.

\section{Immunohistochemical Profile}

The immunohistochemistry findings are summarized in Table 2. Tumors showed nuclear expression of LEF1 (94.2\%), $\beta$-catenin (98.4\%), vimentin (97.5\%), CD10 (66.7\%), CD56 (88.8\%), Syn (66.7\%), and CD99 (7.1\%) (Figure 2). Most tumors had a low Ki-67 index $(<5 \%)$, and nine cases $(14.3 \%)$ had a proliferation index $\geq 5 \%$. LEF1 protein expression was detected in SPNs, NETs, PDACs, pancreatoblastomas, and the normal pancreatic tissue. Further, LEF1 was positively expressed in 49 of the 52 cases of SPN. Meanwhile, in the control group, only five pancreatoblastoma specimens stained positive for LEF1 (Figure 2C), while all others stained negative. However, there were obvious differences in the histomorphology between SPNs and pancreatoblastomas. Pancreatoblastomas are rich in epithelial cells and have a "map-like" appearance under a low-power microscope, with characteristic squamous bodies. The results showed that LEF1 has a high sensitivity $(94.2 \%)$, specificity $(93.8 \%)$, positive predictive value (PPV) $(90.7 \%)$, and negative predictive value (NPV) $(96.2 \%)$ for SPNs. $\beta$-catenin has a high sensitivity (98.4\%), NPV (97.7\%) and low specificity (52.5\%),
Table 2 Immunohistochemical Findings

\begin{tabular}{|l|l|l|}
\hline Marker & Total (n) & Positive (\%) \\
\hline LEFI & 52 & $49(94.2)$ \\
\hline$\beta$-catenin & 63 & $62(98.4)$ \\
\hline Vimentin & 40 & $39(97.5)$ \\
\hline CDI0 & 33 & $22(66.7)$ \\
\hline CD56 & 27 & $24(88.9)$ \\
\hline Syn & 36 & $24(66.7)$ \\
\hline CD99 & 56 & $4(7.1)$ \\
\hline PR & 28 & $21(75)$ \\
\hline AACT & 35 & $34(97.1)$ \\
\hline CK & 38 & $24(62.1)$ \\
\hline CgA & 33 & $3(9.1)$ \\
\hline CEA & 3 & $1(33.3)$ \\
\hline NSE & 28 & $19(67.9)$ \\
\hline Ki-67 & $63 \%$ \\
$\geq 5 \%$ & 63 & $94(85.7)$ \\
\hline
\end{tabular}

Abbreviations: Syn, synaptophysin; PR, progesterone receptor; AACT, $\alpha \mathrm{I}$-antichymotrypsin chromogranin $\mathrm{A}$; CK, cytokeratin; $\mathrm{CgA}$, chromogranin $\mathrm{A}$; CEA, carcinoembryonic antigen; NSE, neuron-specific enolase.

and a positive predictive value (62.0\%) for SPNs. Therefore, the combination of LEF1 is an effective supplement and improvement for the traditional diagnostic markers.

\section{Risk Factors and Follow-Up}

All patients were followed up until January 2020, and the median follow-up time was 42 months (range, 11-126 months). Among the 63 patients, 5 were lost to follow-up and complete data were obtained for the remaining 58 SPN patients. There were nine patients with aggressive SPN biological behavior, including three patients $(4.8 \%)$ with local recurrence and six patients $(9.6 \%)$ with metastasis (4, liver metastasis; 1 , pelvic metastasis; and 1, liver with omentum, ovary, and cervix metastases). Among them, 3 patients died, while the remaining 49 patients were generally in good condition and survived without a recurrence or metastasis at 


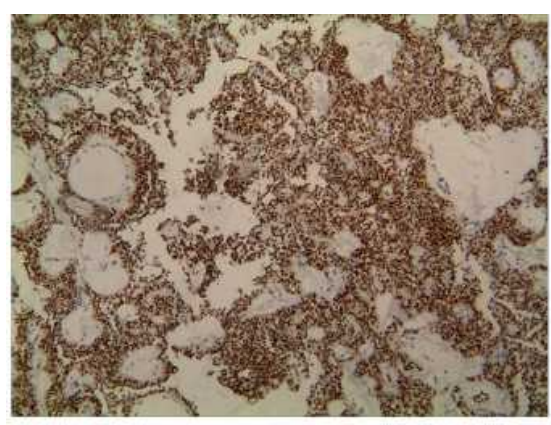

A

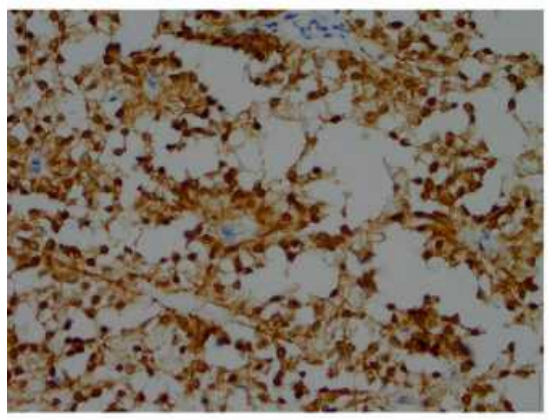

D

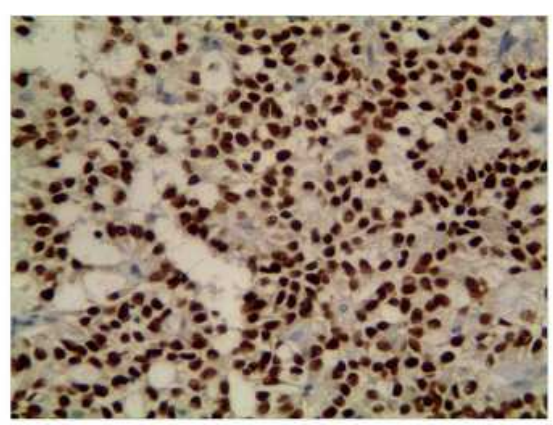

B

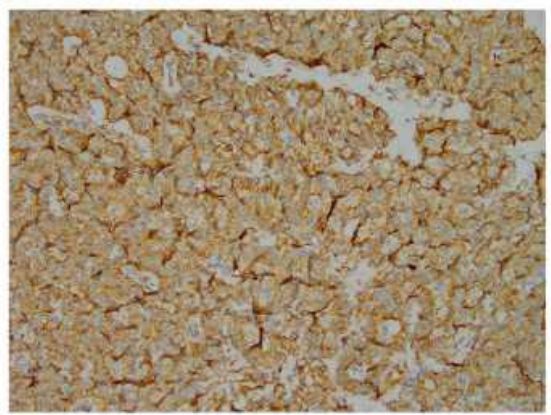

E

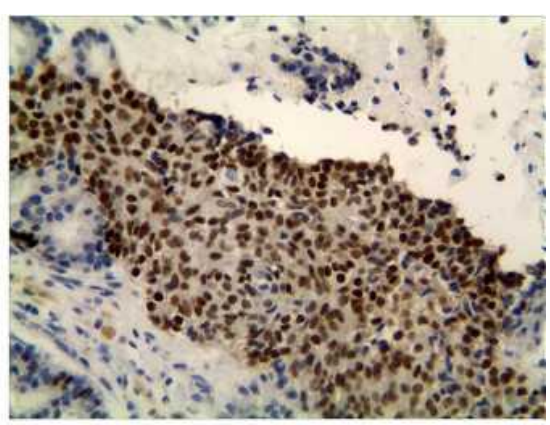

C

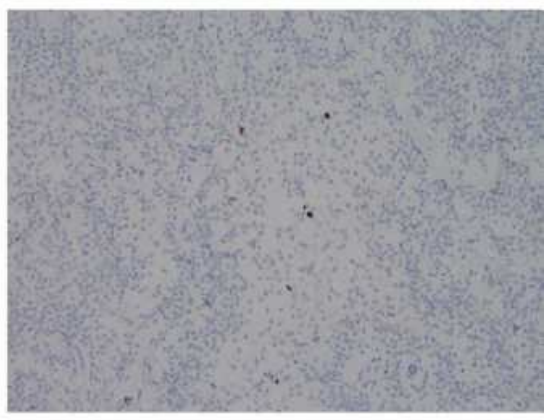

F

Figure 2 Immunohistochemical staining (EnVision Method). (A and B) LEFI is positively expressed in the nucleus of the tumor cells at $\times 100$ and $\times 400$ magnification, respectively. (C) LEFI is positively expressed in the nucleus of the pancreatoblastoma tumor cells (magnification, $\times 400$ ). (D) $\beta$-catenin is positively expressed in the nucleus and cytoplasm of the tumor cells (magnification, $\times 400$ ). (E) Vimentin is positively expressed in the cytoplasm of tumor cells (magnification, $\times 200$ ). (F) Ki-67 proliferation index of the tumor cells is low, and the nucleus is positively expressed (magnification, $\times 200$ ).

the end of the follow-up. Of the 63 patients, $9(14.3 \%)$ had a Ki-67 index $\geq 5 \%, 22(34.9 \%)$ had a tumor diameter $\geq 8 \mathrm{~cm}$, and $5(7.9 \%)$ had lymph node metastasis.

Of the 58 patients with complete follow-up data (Table 3 ), only 9 patients (15.5\%) had Ki-67 index $\geq$ $5 \%$, 22 patients $(37.9 \%)$ had a tumor size $\geq 8 \mathrm{~cm}$, and 4 patients $(6.9 \%)$ had lymph node metastasis. We found that the Ki-67 index $(P<0.001)$, tumor size $(P=$ $0.010)$, and lymph node metastasis $(P=0.011)$ significantly correlated with OS (Figure 3 ). However, sex, age, tumor location, tumor infiltration, presence of mitotic figures, atypia, vascular invasion, and necrosis did not influence OS $(P>0.05)$. Significant univariate analyses were incorporated into multivariate Cox regression analysis, and the results showed that the Ki-67 index $(95 \%$ CI: $1.273-26.777, P=0.023$ ) was an independent risk factor for aggressive behavior (Table 4).

\section{Discussion}

SPN is a rare neoplasm, accounting for only $1-3 \%$ of all pancreatic tumors, and most have low malignant potential and inert biological behavior. ${ }^{11-13}$ The characteristics of SPNs are similar to those of other pancreatic neoplasms; thus, pathological diagnosis can be difficult. Furthermore, there are currently no diagnostic biomarkers specific for SPN.

SPNs can occur at any age, but is mainly observed in young women in their $30 \mathrm{~s} .{ }^{14}$ Fifty-one patients in this study were women, and their average age was 33 years. While SPNs have no specific symptoms, the most common one is abdominal pain. ${ }^{13}$ Further, approximately $1 \%$ of SPNs are located in the pancreatic head, and these patients often present with jaundice. ${ }^{3}$ In our study, one patient presented with jaundice as the first symptom, which may have been related to the tumor located in the head of the pancreas. The preoperative diagnosis of SPN is mainly dependent on an imaging examination. ${ }^{15}$ Approximately $80 \%$ of patients have typical CT or magnetic resonance imaging features of solid and cystic or solid tumors with uneven density within the capsule. Further, most tumors have been found to be round, with lobulated tumors being rare. ${ }^{16}$ While an SPN can occur anywhere in the pancreas, it 
Table 3 Comparison of Clinicopathological Features Between Cases with Aggressive Behavior $(n=9)$ and Indolent Behavior $(n$ = 49)

\begin{tabular}{|c|c|c|c|c|}
\hline Factors & & $\begin{array}{l}\text { Aggressive } \\
(n=9)\end{array}$ & $\begin{array}{l}\text { Indolent } \\
(n=49)\end{array}$ & $P$ value \\
\hline \multirow[t]{2}{*}{ Sex } & Male & 2 & 10 & \\
\hline & Female & 7 & 39 & 0.879 \\
\hline \multirow[t]{2}{*}{ Age (years) } & $<35$ & 5 & 30 & \\
\hline & $\geq 35$ & 4 & 19 & 0.574 \\
\hline \multirow[t]{5}{*}{ Location } & Head & 3 & 11 & \\
\hline & Body & I & 4 & \\
\hline & Tail & 2 & 15 & \\
\hline & $\begin{array}{l}\text { Body and } \\
\text { tail }\end{array}$ & 3 & 16 & \\
\hline & $\begin{array}{l}\text { Outside } \\
\text { pancreas }\end{array}$ & 0 & 3 & 0.799 \\
\hline \multirow[t]{2}{*}{ Symptoms } & Present & 6 & 26 & \\
\hline & Absent & 3 & 23 & 0.622 \\
\hline \multirow{2}{*}{$\begin{array}{l}\text { Tumor size } \\
\text { (cm) }\end{array}$} & $<8$ & 2 & 34 & \\
\hline & $\geq 8$ & 7 & 15 & 0.01 \\
\hline \multirow[t]{2}{*}{ Ki-67 index } & $<5 \%$ & 4 & 45 & \\
\hline & $\geq 5 \%$ & 5 & 4 & $<0.001$ \\
\hline \multirow{2}{*}{$\begin{array}{l}\text { Tumor } \\
\text { infiltration }\end{array}$} & Present & 6 & 19 & \\
\hline & Absent & 3 & 30 & 0.354 \\
\hline \multirow[t]{2}{*}{ Mitosis } & Present & 2 & 8 & \\
\hline & Absent & 7 & 41 & 0.363 \\
\hline \multirow{2}{*}{$\begin{array}{l}\text { Cellular } \\
\text { atypia }\end{array}$} & Present & 0 & I & \\
\hline & Absent & 9 & 48 & 0.650 \\
\hline \multirow{2}{*}{$\begin{array}{l}\text { Vascular } \\
\text { invasion }\end{array}$} & Present & 2 & 4 & \\
\hline & Absent & 7 & 45 & 0.148 \\
\hline \multirow{2}{*}{$\begin{array}{l}\text { Lymph node } \\
\text { metastasis }\end{array}$} & Present & 2 & 2 & \\
\hline & Absent & 7 & 47 & 0.011 \\
\hline \multirow[t]{2}{*}{ Necrosis } & Present & 4 & 25 & \\
\hline & Absent & 5 & 24 & 0.749 \\
\hline \multirow[t]{2}{*}{ Calcification } & Present & 4 & 29 & \\
\hline & Absent & 5 & 20 & 0.353 \\
\hline
\end{tabular}

has a predilection for the tail. ${ }^{17}$ In the present study, 17 SPNs $(27.0 \%)$ were located in the pancreatic tail and 22 (34.9\%) in the pancreatic body and tail. After ruling out the possibility of tumor metastasis, three patients $(4.8 \%)$ had primary SPNs in the retroperitoneal region.

SPN has a large tumor volume, complete capsule, and clear boundary within the surrounding tissues. ${ }^{18}$ It is composed of solid, pseudopapillary, and cystic areas. The cells in the solid region are similar in size and shape and are arranged in clusters around the blood vessels. The pseudopapillary area comprises pseudopapillary structures around the central small vessels of tumor cells. Hemorrhage and necrosis are common in the cystic areas. Hematoxylin and eosin staining commonly shows an eosinophilic tumor cell cytoplasm and a round and centered nucleus, with nuclear mitosis and atypia being rare.

There are no specific immunohistochemical biomarkers for SPNs at present, and $\beta$-catenin, vimentin, Syn, CD10, and PR are usually combined to improve the diagnosis rate. ${ }^{17}$ LEF1 plays a key role in the transcriptional activation of the Wnt/CTNNB1 signaling pathway, and the mutation of the third exon in CTNNB1 is related to the occurrence of SPN, suggesting that the LEF1 protein may play an important role in the diagnosis of SPN. ${ }^{19}$ In this study, the LEF1 protein was positively expressed in 49 of the 52 SPN cases, whereas it was negatively expressed in all 25 cases of NET, 25 cases of PDAC, and 25 cases of normal pancreatic tissue in the control group. Although LEF1 was positive in five cases of pancreatoblastomas, there were significant differences in their histomorphologies. A recent study reported that the CD99 protein yields unique paranuclear spots in SPNs and can be used as a diagnostic biomarker. ${ }^{20}$ However, only 4 of the 56 patients in this study tested positive for CD99. The difference in results may be related to the clone numbers and sensitivities of different antibodies. Meanwhile, we found that LEF1 was a specific biomarker for the diagnosis and differential diagnosis of SPN.

In general, SPNs have good prognosis after surgery, with a recurrence rate of only $10-15 \%$ and a mortality rate of only $2 \%{ }^{8}$ The most common metastatic target organ of SPN is the liver, while other rare sites include the greater omentum, inguinal lymph nodes, and lungs. ${ }^{11,21}$ Among the 63 patients with SPN in this study, six had distant metastases, of whom three died and three had local recurrence after surgery. In this study, the incidence of SPNs with aggressive behavior 
A

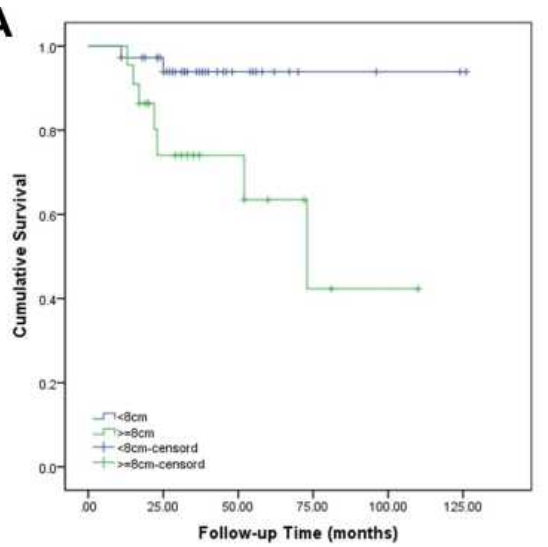

B

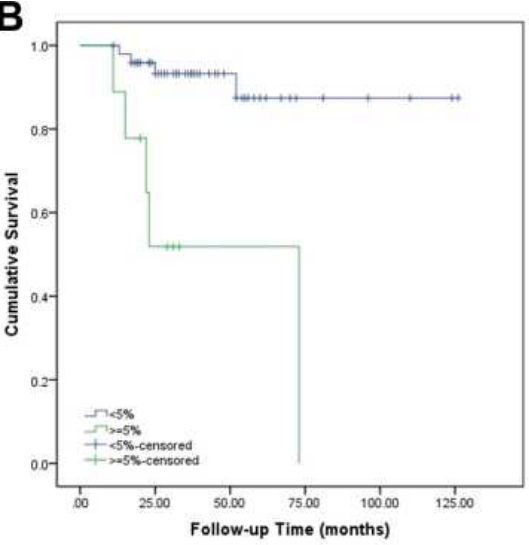

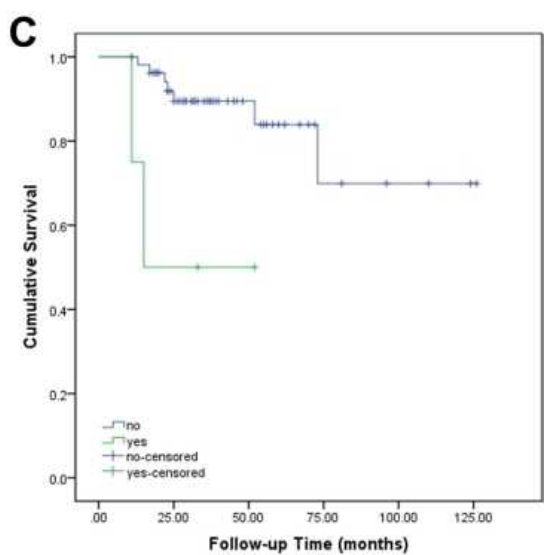

Figure 3 Kaplan-Meier disease-free survival curves according to the $(\mathbf{A})$ tumor size $(P=0.0 \mathrm{I} 0)$, $(\mathbf{B})$ Ki-67 index $(P<0.00 \mathrm{I})$, and $(\mathbf{C})$ lymph node metastasis $(P=0.0 \mathrm{II})$.

was $14.3 \%$, and the associated mortality rate was $4.8 \%$, consistent with most reports.

The risk factors for the malignant behavior and poor prognosis of SPNs have not been fully elucidated to date, and the results have varied markedly among studies. Some reports have suggested that microscopic pathological characteristics, such as cell pleomorphism, prominent necrosis, perineural invasion of the surrounding tissue, and multiple mitotic figures, can predict the malignant potential of SPNs. ${ }^{8,22}$ There are also reports that male sex, incomplete capsules, a young age $(<13.5$ years), positive surgical margins during the initial tumor resections, and large tumor sizes may be associated with SPN recurrence. ${ }^{23-27}$ However, one study indicated that there was no significant correlation between the malignant potential of SPNs and tumor size. ${ }^{28}$ The difference may be related to the number of samples, particularly the small sample size of the patients with aggressive SPN biological behaviors and poor prognosis. In the current study, nine patients showed aggressive SPN biological behavior, of whom three had local recurrence and six had metastases. Three of the six patients with metastases died. Tumor diameter $\geq 8 \mathrm{~cm}$, a Ki-67 index $\geq 5 \%$, and lymph node metastasis significantly correlated with OS, whereas sex, age, location, peripheral invasion, mitotic figures, and focal necrosis did not. In addition, Ki-67 index is an independent risk factor affecting SPN aggressive behavior. This study has some limitations. The sample size of aggressive SPN cases was small, and five patients were lost to followup. However, it provided a direction for future research, a reference for clinicians to diagnose SPNs and predict their malignant behavior, and a reminder to doctors to follow-up on these patients closely.

\section{Conclusion}

In conclusion, SPNs tend to occur in young women. They lack specific clinical manifestations and have low malignant potential. They present with an inert process; however, a few patients display invasive behaviors and have poor prognosis. LEF1 is a novel effective immune marker for an SPN. A large tumor size, high proliferation index, and lymph node metastasis may be risk factors for the aggressive behavior and poor prognosis of an SPN.

Table 4 Multivariate Cox Regression Analysis Results of Overall Survival

\begin{tabular}{|c|c|c|c|c|c|c|c|c|}
\hline & \multirow[t]{2}{*}{ B } & \multirow[t]{2}{*}{ SE } & \multirow[t]{2}{*}{ Wald $\chi 2$} & \multirow[t]{2}{*}{ df } & \multirow[t]{2}{*}{ Sig. } & \multirow[t]{2}{*}{$\operatorname{Exp}(B)$} & \multicolumn{2}{|c|}{$95.0 \% \mathrm{Cl}$} \\
\hline & & & & & & & Lower & Upper \\
\hline Ki-67 index & 1.765 & 0.777 & 5.157 & I & 0.023 & 5.839 & 1.273 & 26.777 \\
\hline Lymph node metastasis & $1.67 \mid$ & 0.867 & 3.715 & I & 0.054 & 5.320 & 0.972 & 29.106 \\
\hline Tumor size & 0.977 & 0.906 & 1.162 & 1 & 0.281 & 2.657 & 0.450 & 15.703 \\
\hline
\end{tabular}




\section{Abbreviations}

CT, computed tomography; H\&E, hematoxylin and eosin; NET, neuroendocrine tumor; OS, overall survival; PDAC, pancreatic ductal adenocarcinoma; SNP, solidpseudopapillary neoplasm; Syn, synaptophysin; PPV, positive predictive value; NPV, negative predictive value.

\section{Data Sharing Statement}

No additional data are available.

\section{Ethics Approval and Informed Consent}

This study was reviewed and approved by the Ethics Committee of Bengbu Medical College. All patients provided written informed consent.

\section{Acknowledgments}

The authors would like to thank Cai Ben for their significant contribution to data analysis.

\section{Author Contributions}

All authors made substantial contributions to conception and design, acquisition of data, or analysis and interpretation of data; took part in drafting the article or revising it critically for important intellectual content; agreed to submit to the current journal; gave final approval of the version to be published; and agree to be accountable for all aspects of the work.

\section{Funding}

This study was supported by the Natural Science Foundation of Anhui Province (No.1908085MH275); the Key Project of Natural Science Foundation of Bengbu Medical College (BYKF1710); the Joint Science and Technology Project of Bengbu City-Bengbu Medical College (BYLK201812).

\section{Disclosure}

The authors report no conflicts of interest in this work.

\section{References}

1. Dinarvand P, Lai JP. Solid pseudopapillary neoplasm of the pancreas: a rare entity with unique features. Arch Pathol Lab Med. 2017;141 (7):990-995. doi:10.5858/arpa.2016-0322-RS

2. Jutric Z, Rozenfeld Y, Grendar J, et al. Analysis of 340 patients with solid pseudopapillary tumors of the pancreas: a closer look at patients with metastatic disease. Ann Surg Oncol. 2017;24(7):2015-2022. doi:10.1245/s10434-017-5772-z
3. Papavramidis T, Papavramidis S. Solid pseudopapillary tumors of the pancreas: review of 718 patients reported in English literature. $J$ Am Coll Surgeons. 2005;200(6):965-972. doi:10.1016/j.jamcollsurg.2005.02.011

4. Lanke G, Ali FS, Lee JH. Clinical update on the management of pseudopapillary tumor of pancreas. World $J$ Gastrointest Endosc. 2018;10(9):145-155. doi:10.4253/wjge.v10.i9.145

5. Notohara K, Hamazaki S, Tsukayama C, et al. Solid-pseudopapillary tumor of the pancreas: immunohistochemical localization of neuroendocrine markers and CD10. Am J Surg Pathol. 2000;24 (10):1361-1371. doi:10.1097/00000478-200010000-00005

6. Guo Y, Yuan F, Deng H, Wang HF, Jin WL, Xiao JC. Paranuclear dot-like immunostaining for CD99: a unique staining pattern for diagnosing solid-pseudopapillary neoplasm of the pancreas. Am J Surg Pathol. 2011;35(6):799-806. doi:10.1097/PAS.0b013e318219c036

7. Miao L, Lei R, Guo M, Yang H. Solid pseudopaillary neoplasm of the pancreas: analysis of clinicopathological and immunohistochemical features in 10 cases. Int $J$ Clin Exp Pathol. 2018;11 (10):5072-5078.

8. Hao EIU, Hwang HK, Yoon DS, Li JW, Kang CM. Aggressiveness of solid pseudopapillary neoplasm of the pancreas: a literature review and meta-analysis. Medicine. 2018;97(49):e13147. doi:10.1097/ MD.0000000000013147

9. Kang CM, Choi HS, Kim SC, Lee WJ, Choi DW, Kim SW. Korean Pancreatic Surgery Club. Predicting recurrence of pancreatic solid pseudopapillary tumors after surgical resection: a multicenter analysis in Korea. Ann Surg. 2014;260(2):348-355. doi:10.1097/ SLA.0000000000000583

10. Zhang H, Wang W, Yu S, Xiao Y, Chen J. The prognosis and clinical characteristics of advanced (malignant) solid pseudopapillary neoplasm of the pancreas. Tumour Biol. 2016;37(4):5347-5353. doi:10.1007/s13277-015-4371-5

11. Tjaden C, Hassenpflug M, Hinz U, et al. Outcome and prognosis after pancreatectomy in patients with solid pseudopapillary neoplasms. Pancreatology. 2019;19(5):699-709. doi:10.1016/j.pan.2019.06.008

12. Wang XG, Ni QF, Fei JG, Zhong ZX, Yu PF. Clinicopathologic features and surgical outcome of solid pseudopapillary tumor of the pancreas: analysis of 17 cases. World J Surg Oncol. 2013;11:38. doi:10.1186/1477-7819-11-38

13. Reddy S, Cameron JL, Scudiere J, et al. Surgical management of solid-pseudopapillary neoplasms of the pancreas (Franz or Hamoudi tumors): a large single-institutional series. J Am Coll Surg. 2009;208 (5):950-959. doi:10.1016/j.jamcollsurg.2009.01.044

14. Ye J, Ma M, Cheng D, et al. Solid-pseudopapillary tumor of the pancreas: clinical features, pathological characteristics, and origin. J Surg Oncol. 2012;106(6):728-735. doi:10.1002/jso.23195

15. Anil G, Zhang J, Al Hamar NE, Nga ME. Solid pseudopapillary neoplasm of the pancreas: CT imaging features and radiologic-pathologic correlation. Diagn Interv Radiol. 2017;23 (2):94-99. doi:10.5152/dir.2016.16104

16. Hu S, Zhang H, Wang X, et al. Asymptomatic versus symptomatic solid pseudopapillary tumors of the pancreas: clinical and MDCT manifestations. Cancer Imaging. 2019;19(1):13. doi:10.1186/s40644019-0198-4

17. Li L, Li J, Hao C, et al. Immunohistochemical evaluation of solid pseudopapillary tumors of the pancreas: the expression pattern of CD99 is highly unique. Cancer Lett. 2011;310(1):9-14. doi:10.1016/j.canlet.2011.04.017

18. Kim JH, Lee JM. Clinicopathologic review of 31 cases of solid pseudopapillary pancreatic tumors: can we use the scoring system of microscopic features for suggesting clinically malignant potential? Am Surg. 2016;82(4):308-313. doi:10.1177/000313 481608200414

19. Singhi AD, Lilo M, Hruban RH, Cressman KL, Fuhrer K, Seethala RR. Overexpression of lymphoid enhancer-binding factor 1 (LEF1) in solid-pseudopapillary neoplasms of the pancreas. Mod Pathol. 2014;27(10):1355-1363. doi:10.1038/modpathol.2014.40 
20. Ardengh JC, Lopes CV, Venco FE, Machado MA. Diagnosis of pancreatic solid pseudopapillary neoplasms using cell-blocks and immunohistochemical evaluation of endoscopic ultrasound-guided fine needle aspiration biopsy specimens. Cytopathology. 2021;32 (1):50-56. doi:10.1111/cyt.12905

21. Lee HS, Kim HK, Shin BK, Choi JH, Choi YJ, Kim HY. A rare case of recurrent metastatic solid pseudopapillary neoplasm of the pancreas. J Pathol Transl Med. 2017;51(1):87-91. doi:10.4132/ jptm.2016.06.16

22. Kim MJ, Choi DW, Choi SH, Heo JS, Sung JY. Surgical treatment of solid pseudopapillary neoplasms of the pancreas and risk factors for malignancy. $B r \quad J$ Surg. 2014;101(10):1266-1271. doi:10.1002/ bjs. 9577

23. Machado MCC, Machado MAC, Bacchella T, Jukemura J, Almeida JL, Cunha JE. Solid pseudopapillary neoplasm of the pancreas: distinct patterns of onset, diagnosis, and prognosis for male versus female patients. Surgery. 2008;143(1):29-34. doi:10.1016/j. surg.2007.07.030

24. Song H, Dong M, Zhou J, Sheng W, Zhong B, Gao W. Solid pseudopapillary neoplasm of the pancreas: clinicopathologic feature, risk factors of malignancy, and survival analysis of 53 cases from a single center. Biomed Res Int. 2017;2017:5465261. doi:10.1155/ $2017 / 5465261$
25. Irtan S, Galmiche-Rolland L, Elie C, et al. Recurrence of solid pseudopapillary neoplasms of the pancreas: results of a nationwide study of risk factors and treatment modalities. Pediatr Blood Cancer. 2016;63(9):1515-1521. doi:10.1002/pbc.25986

26. Lee SE, Jang JY, Hwang DW, Park KW, Kim SW. Clinical features and outcome of solid pseudopapillary neoplasm: differences between adults and children. Arch Surg. 2008;143(12):1218-1221. doi:10.1001/archsurg.143.12.1218

27. Butte JM, Brennan MF, Gonen M, et al. Solid pseudopapillary tumors of the pancreas. Clinical features, surgical outcomes, and long-term survival in 45 consecutive patients from a single center. J Gastrointest Surg. 2011;15(2):350-357. doi:10.1007/s11605-0101337-1

28. De Robertis R, Marchegiani G, Catania M, et al. Solid pseudopapillary neoplasms of the pancreas: clinicopathologic and radiologic features according to size. AJR Am J Roentgenol. 2019;213 (5):1073-1080. doi:10.2214/AJR.18.20715

\section{Publish your work in this journal}

Cancer Management and Research is an international, peer-reviewed open access journal focusing on cancer research and the optimal use of preventative and integrated treatment interventions to achieve improved outcomes, enhanced survival and quality of life for the cancer patient.
The manuscript management system is completely online and includes a very quick and fair peer-review system, which is all easy to use. Visit http://www.dovepress.com/testimonials.php to read real quotes from published authors. 